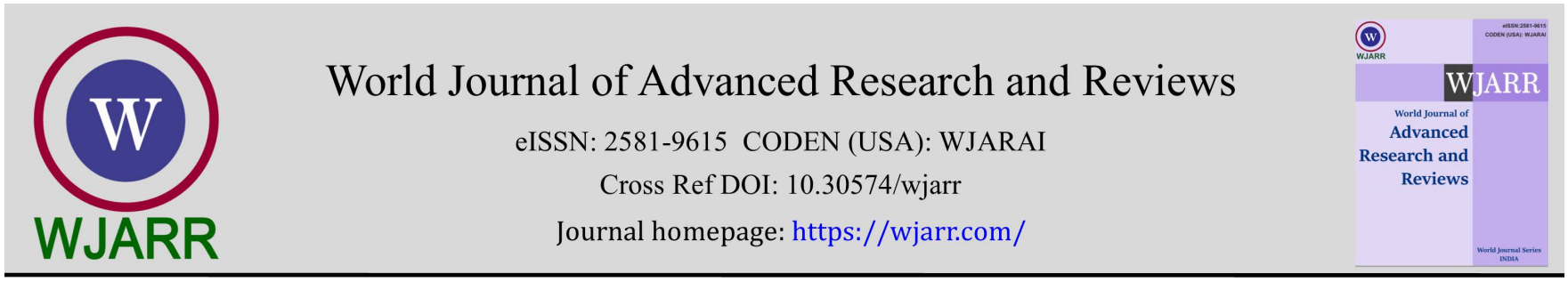

(SHORT COMMUNiCATION)

\title{
Capacity building programs for COVID-19 outbreak in Duhok governorate: A short report
}

\author{
Muayad Aghali Merza ${ }^{1, *}$ and Bayram Dawod Ahmed ${ }^{2}$ \\ ${ }^{1}$ Department of Internal Medicine, Azadi Teaching Hospital, College of Pharmacy, University of Duhok, Iraqi Kurdistan. \\ ${ }^{2}$ Medical laboratory science department, College of health science, University of Duhok, Iraqi Kurdistan.
}

World Journal of Advanced Research and Reviews, 2022, 13(01), 347-350

Publication history: Received on 08 December 2021; revised on 10 January 2022; accepted on 12 January 2022

Article DOI: https://doi.org/10.30574/wjarr.2022.13.1.0036

\begin{abstract}
Considering Iraqi Kurdistan geographical area, there was great concern with regard to Iran's COVID-19 situation as it was alarming to the doors of Kurdistan. In response, a framework named as "support of public basic services for vulnerable persons in Duhok Governorate" was performed by Directorate General of Health in collaboration with the Deutsche Gesellschaft für Internationale Zusammenarbeit (GIZ) organization. The ultimate results were: Out-patient and in-patient management guidelines for COVID-19 cases in Duhok Governorates; Recommended types of personal protective equipment (PPE) in the context of COVID-19; The methods of using and disposing of mask, gloves, and PPE for the healthcare providers.
\end{abstract}

Keywords: COVID-19; Duhok; Training courses; Guideline

\section{Introduction}

The outbreak of COVID-19 was first recognized in Wuhan city, China in December 2019. Thereafter it spread to other countries of different continents. Considering our geographical area, there was great concern with regard to Iran's COVID-19 situation as it was alarming to the doors of Kurdistan. There were suspected and confirmed COVID-19 cases in Kurdistan with insufficient clinical experience of the healthcare workers [1, 2].

In response, a framework named as "Support of public basic services for vulnerable persons in Duhok Governorate" was performed by Directorate General of Health (DGOH) in collaboration with the Deutsche Gesellschaft für Internationale Zusammenarbeit (GIZ) organization [3]. The aims were to develop and implement capacity-building measures to upgrade the skills of healthcare providers to enable to respond to COVID-19 patients with the special emphasis on emergency health service providers.

The program was organized by “Continuing Professional Development Department, DGOH , Duhok, Kurdistan, Iraq” and supported by "GIZ.

\section{The consultancy methodology and approach focused on addressing the following health issues.}

- To ensure effective coordination and sharing updated information between different teams involved in the implementation of the emergency response program against the COVID-19.

- To ensure effective integration of the emergency response program against the COVID-19 outbreak into longerterm programs and overall strategic objectives of the country's strategy.

\footnotetext{
* Corresponding author: Muayad Aghali Merza

Department of Internal Medicine, Azadi Teaching Hospital, College of Pharmacy, University of Duhok, Iraqi Kurdistan.

Copyright (C) 2022 Author(s) retain the copyright of this article. This article is published under the terms of the Creative Commons Attribution Liscense 4.0.
} 
- To support the DGOH Duhok preparedness plan against the COVID-19 outbreak for multi-threat response in the health sector and to enhance the health emergency coordination mechanism.

- To support and strengthen the capabilities of DGOH Duhok health facilities, to reduce the risk of the disease spread.

- To provide technical guidance for the design and implementation of the emergency preparedness and response plan against COVID-19

- To prepare supporting tools and culturally sensitive mechanisms to protect and improve public health during the COVID-19 outbreak.

- To organize and conduct required training activities for the health staff about the COVID-19 disease including on-job mentoring and coaching.

- To develop and implement effective health risk communication plans to mitigate and respond to public concerns about emergency health risks associated with COVID-19 infections.

\subsection{Consultancy team and its tasks}

The team of consultants consisted of different specialties including an infectious disease specialist; a family medicine doctor; and an internal medical doctor, two pharmacists, and a college nurse. The medical doctors were trained by members of the mentioned team in districts all over Duhok Governorate. The program was implemented under the direct supervision of Duhok DGOH Director General and Head of Technical Affairs Department in close coordination with the senior advisor of GIZ health Program-Duhok office. The capacity building was supported by some laboratory specialists through holding a series of presentations on the laboratory detection of COVID-19.

Duhok DGOH assigned an infectious disease specialist as the supervisor of Duhok COVID-19 Specialized Hospitals. The capacity building programs consisted of scientific symposiums; guidelines development; training courses; on-job training; and technical support [1].

Scientific symposium and training courses were implemented through the following syllabuses. The syllabuses were: updates on COVID-19 and management guidelines in Duhok, proper use of personal protective equipment (PPE), infection control and prevention in the context of COVID-19, Duhok preventive health directorate measures, laboratory detection of COVID-19, introduction to Duhok COVID-19 specialized hospitals, and an introduction to Kavin center for suspected COVID-19 cases.

Precautions of the Ministry of Health were considered during capacity building programs; such as distance between participants, hygiene and infection prevention and control measures, providing masks and gloves for the participants, and using alcohol-based gel, etc [4] Azadi Scientific Symposium included: Italy Experience, Live Video Conference with Consultant in Infectious Diseases - San Raffaele Hospital in Milan.

Training courses focused on specialist medical doctors who were in the frontline of COVID-19 management. Thirteen training courses were conducted all-over Duhok Governorate.

\subsection{Guidelines development}

Three local guidelines for the management of the suspected and confirmed cases of the COVID-19 were developed for Duhok Governorate. The guidelines were developed through a series of revisions and updates of the local situation and World Health Organization protocols as follows [5].

- Guideline I Out-patient and in-patient management; guidelines for COVID-19 cases in Duhok Governorate (Fig 1) [1].

- $\quad$ Guideline II Recommended types of PPE in the context of COVID-19.

- Guideline III The methods of using and disposing of mask, gloves, and PPE for the healthcare providers

\subsection{On-job training}

The continuous support on the job training for the healthcare providers working in Duhok COVID-19 Specialized Hospitals and Kavin center for suspected COVID-19 cases was conducted through daily visits and supervision. 


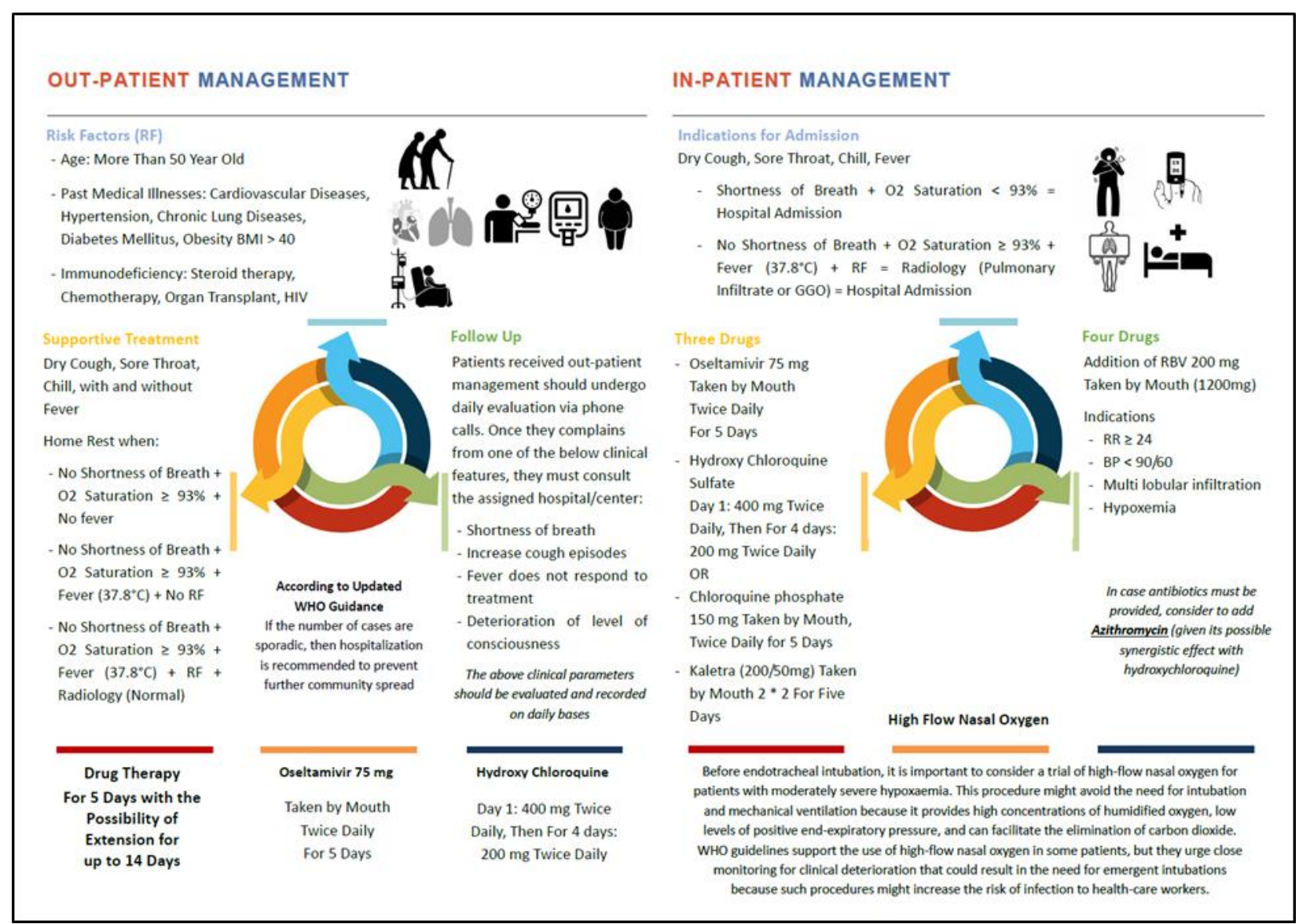

Figure 1 Out-patient and in-patient management guidelines for COVID-19 cases in Duhok Governorate

\subsection{Technical support}

Continuous technical support to operationalize Duhok COVID-19 specialized hospitals was presented to the appropriate personnel. The coordination and referral pathways were improved and the patient's medical profile was developed accordingly [6]. The design of health institutes that deliver services to COVID-19 confirmed and suspected cases were supervised closely.

\subsection{Development of patients' profile}

Technical support to develop the patient's medical profile for admission and follow up of Duhok COVID-19 specialized hospitals and Kavin center for suspected COVID-19 Cases.

\section{Conclusion}

In response to COVID-19 outbreak, several training courses were set by the Directorate General of Health (DGOH) in collaboration with the GIZ organization. Three local guidelines for the management of the suspected and confirmed cases of the COVID-19 were developed for Duhok Governorate. This project aimed at an improved management of COVID-19 patients in Duhok governorate.

\section{Compliance with ethical standards}

\section{Acknowledgments}

We would like to present our profound thanks to GIZ organization for their kind support. Furthermore, we would like to extend our appreciation to Mr. Deldar Morad Abdullah for his incredible help. 


\section{Disclosure of conflict of interest}

The authors declare that they have no conflict of interest.

\section{Funding}

The capacity building programs were funded by GIZ, but this study was supported by the authors only.

\section{References}

[1] Merza MA, Al Mezori AAH, Mohammed HM, Abdulah DM. COVID-19 outbreak in Iraqi Kurdistan: The first report characterizing epidemiological, clinical, laboratory, and radiological findings of the disease. Diabetes \& Metabolic Syndrome: Clinical Research \& Reviews. 2020; 14(4): 547-54.

[2] Almufty HB, Mohammed SA, Abdullah AM, Merza MA. Potential adverse effects of COVID19 vaccines among Iraqi population; a comparison between the three available vaccines in Iraq; a retrospective cross-sectional study. Diabetes \& Metabolic Syndrome: Clinical Research \& Reviews. 2021; 15(5): 102207.

[3] Tag Archives | Deutsche Gesellschaft für Internationale Zusammenarbeit (GIZ).

[4] Merza MA, Abdulah DM, Mohammed HM, Yones AM. Epidemiological Trends of the 2019 Coronavirus Disease in Iraqi Kurdistan. Disaster medicine and public health Preparedness. 2021; 1.

[5] World Health Organization. Overview of public health and social measures in the context of COVID-19: interim guidance, 18 May 2020. World Health Organization. 2020.

[6] Merza MA, Aswad SM, Sulaiman HM, Abdulah DM, Rasheed WS, Taib NI. Clinical and epidemiological characteristics and outcomes of Coronavirus disease-19 patients in a large longitudinal study. International journal of health sciences. 2021; 15(4): 29. 